\title{
OPTIMIZATION OF THE PYROLYSIS OIL FRACTION: AN ATTAINABLE REGION APPROACH
}

\author{
Baboloki Chiwara ${ }^{1}$, Emmanuel Makhura ${ }^{1}$, Gwiranai Danha *,1, Nkosikhona Hlabangana ${ }^{2}$, \\ Joshua Gorimbo ${ }^{3}$ and Edison Muzenda \\ ${ }^{1}$ Department of Chemical, Materials and Metallurgical Engineering, College of Engineering and Technology, Botswana International \\ University of Science and Technology, Plot 10071, Boseja Ward, Private Bag 16 Palapye, Botswana \\ ${ }^{2}$ Department of Chemical Engineering, National University of Science and Technology, P.O Box AC 939 Ascot, Bulawayo, Zimbabwe \\ ${ }^{3}$ Department of Chemical Engineering, University of South Africa, Florida Science Campus, Private Bag 1701, Florida, South Africa
}

Article Info:
Received:
15 January 2018
Revised:
18 June 2018
Accepted:
6 August 2018
Available online:
27 August 2018
Keywords:
Plastic solid waste
Pyrolysis
Reverse polymerization
Pyrolysis oil

Article Info:

Received:

Revised:

18 June 2018

Accepted:

Available online:

27 August 2018

Keywords:

Pyrolysis

Pyrolysis oil

\section{INTRODUCTION}

Traditionally, the production of liquid fuels, organic chemicals and energy, has relied heavily on the gasification of coal, distillation of crude oil and hydro-power. As natural resources are becoming depleted, and continue to do so due to the exponential growth of our population, the need to look elsewhere for sources of alternative raw materials and processes is imperative.

Domestic and industrial plastic solid waste (PSW) collection and disposal systems in Botswana are not as efficient as those in other developing African countries like South Africa, Ghana and Ethiopia. Specifically, the mode of disposal of PSW in smaller cities and villages in Botswana is a major concern. Even in bigger cities, the current waste management systems mostly entail use of dumping sites and landfills, where the majority of the waste (Al-Salem et al. 2010) has been identified to be different classes of polymers namely: high density polyethylene (HDPE), low density poly ethylene (LDPE), poly vinyl chloride (PVC), poly propylene (PP), poly styrene (PS) and poly ethylene terephthalate (PET) (Singh et al. 2017)

Although the rate of reaction associated with the biodegradation process of plastic waste is said to be slow that it is kinetically approximated not to be taking place (Guerrero et al. 2013), it is however thermodynamically feasible.
Some waste management researchers (Shah et al. 2008; Das \& Tiwari, 2017 Hahladakis et al. 2018) have argued that pigments used in plastics as well as plastics can be broken down by acidic leachates under certain conditions of temperature $\left(450^{\circ} \mathrm{C}\right)$ and pressure $(2 \mathrm{kPa})$ to give products that are both deleterious and obnoxious to the environment and to the underground water sources which in some areas serve as drinking water for livestock, wildlife and even the rural folk.

Due to these highlighted PSW issues, the Botswana Government has responded to this societal challenge by implementing its environmental policies and inviting some NGOs and private companies on-board in assisting to combat this waste situation. But this approach has not yielded any positive results in villages like Palapye, Pilikwe, Serule and smaller towns like Serowe, Selibe Phikwe and Maun. In these parts of the country, PSW will continue to increase with negative implications on the local municipalities and environment. The major challenge in these locations is mainly the state of the roads, which make it practically impossible for refuse collection trucks to access the domestic and industrial waste. The finances usually allocated to the local municipalities by the central government in order to run their towns is also a constraint as it is never enough to address the water supply, sanitary, accommodation and other service delivery challenges, let alone cater for the 
waste collection and disposal services. Even at a government level, rarely is waste treatment a priority as there are more pressing national issues such as electricity supply, food security, agricultural inputs and mining challenges to take care of.

In this research, we focused on the application of the attainable region method as an optimization technique that has never before been used in the field of waste management, specifically in optimising the pyrolysis oil fraction from plastic waste.

\subsection{Theoretical background}

Botswana is a major market for most South African manufactured products. This is mainly due to the fact that the manufacturing industry in Botswana is hardly existing. This situation poses challenges on proposals of how to recycle PSW as there are no local plastic industries that will process the recycled material. In neighbouring countries such as Zimbabwe and South Africa, there are plastic processing companies like Megapak and Nampak, respectively. These companies have led to the development of downstream recycle companies that supply them with recycled material to be used as feed. These downstream companies have also created a lot of jobs for local people who are willing to collect the PSW.

We propose that PSW should be collected from the villages and processed into finished products that are of economic value to the same villagers. There are four generally acceptable and well developed techniques used to process PSW, namely gasification, hydrogenation, biodegradation and pyrolysis (Marshall \& Farahbakhsh, 2013). For this research, we chose to use a batch pyrolysis method because of its simplicity in design, operation and relative ease in adjusting the experimental parameters.

\subsection{The pyrolysis process}

The pyrolysis process starts with higher molecular chain hydrocarbons (polymers) that are then broken down (cracking) using either heat, a catalyst or hydrogen gas (Al-Salem et al. 2017) into targeted smaller chain hydro-carbons such as pyrolysis oil, tar and char. Plastics, tyres and even coal can be used as feed material to a pyrolysis plant. In general, this process of waste treatment has added advantages over traditional approaches such as incineration in that products of socio-economic value are obtained. Charcoal, tar, oil, wax and combustible gases are some of the products of pyrolysis (Chen et al. 2014) and process parameters can be optimised for maximum production of either the solid, liquid or gaseous products.

Since pyrolysis is basically a thermal degradation process that occurs in the absence of oxygen, most researchers conducted their pyrolysis studies at atmospheric pressure and focused more on the temperature factor (Sharuddin et al. 2016). Other researchers (Martínez et al. 2013; Das \& Tiwari, 2018) focussed on the rate aspect associated with pyrolysis, in which they proved that the product composition and yield are a function of pyrolysis time. The other factors that affect the efficiency of a pyrolysis process are pressure, type of reactor, temperature, residence time and cooling mechanisms (Sharuddin et al. 2016). Investiga- tions on the development and effect of different types of reactors on pyrolysis were reported by Sannita et al., 2012 while Quek and Balasubramanian (2013) reported on the oil characteristics and upgrading techniques.

\subsection{Batch reactor design}

It is generally accepted that the pyrolysis process follows a first order irreversible reaction model, whose integral form (equation 1) is used here to determine the optimum residence time.

\subsubsection{Conversion and reactor sizing}

$-r_{A}=N_{A_{o}} \frac{d X_{A}}{d t}(\mathrm{mols} / \mathrm{s})$

Where:

$N_{A_{o}}$ is the initial number of moles of the reactant $A$

$d X_{A}$ is the change in conversion of reactant $A$

$d t$ is the change in time

$-r_{A}$ is the rate of reaction with respect to reactant $A$

$V$ is the volume of the reactor

In the integral form:

$d t=\frac{N_{A 0}}{V} \frac{d X_{A}}{r_{A}}$

Since the reactor was for a constant volume, the equations above reduces to:

$t=\frac{N_{A 0}}{V} \int_{X_{A 0}}^{X_{A}} \frac{d X_{A}}{-r_{A}}$

The pyrolysis of plastics is defined by an irreversible uni-molecular first order reaction of the form ( $A \rightarrow$ products):

$-r_{A}=-\frac{d C_{A}}{d t}=k C_{A}$

Where:

$k$ is the rate constant

The equation simplifies to:

$-\ln \left(1-X_{A}\right)=k t$

The kinetic parameters of pyrolysis under isothermal conditions as given by (Khaghanikavkani \& Farid, 2011) are:

$\mathrm{Ea}=164.15 \mathrm{~kJ} / \mathrm{mol}$

$\mathrm{K}_{0}=4.89 \times 10^{7} / \mathrm{sec}$

The rate constant is therefore calculated from the Arrhenius equation:

$$
\begin{aligned}
k & =4.89 \times 10^{7} e^{-\left(\frac{164.15 \times 10^{3}}{(8.314)}\right)} \\
& =1.8 \times 10^{-4} / \mathrm{sec}
\end{aligned}
$$

The residence time was the calculated from the integrated rate law equation for a first order reaction with a conversion of $70 \%$.

$-\ln \left(1-X_{A}\right)=k t$

$-\ln (1-0.7)=1.8 \times 10^{-4}(t)$

$t=1.85$ hours $\cong 2 \mathrm{hrs}$

\section{MATERIALS AND METHODS}

In preparing the feed sample that was used in this investigation, $80 \mathrm{~kg}$ of plastic waste was collected from the 
Palapye landfill site, in Botswana. This waste was then grouped into the six different classes of plastics namely: HDPE, LPDE, PVC, PET, PP and PS using their resin identification number (RIN). Other different classification techniques that could have been used, if resources permitted include froth flotation, laser induced breakdown spectroscopy and the X-ray fluorescence spectrometer. The next step in the experimental procedure was to combine the HDPE and LDPE fractions together before taking the mixture to the laboratory scale plastic shredder for size reduction. The standard particle size analysis method was then carried out on a $100 \mathrm{~g}$ cone and quartered shredded sample, using a stack of sieves arranged in the route mean square technique and having a top size of $2400 \mu \mathrm{m}$, bottom size of $300 \mu \mathrm{m}$ placed over a pan and electric shaker for 20 mins. After a particle size distribution (PSD) analysis, the experimental setup was arranged as shown in Figure 1. A measured $1000 \mathrm{~g}$ sample of the size reduced and homogenised material was then introduced into the batch reactor, heated using an electric coil for periods ranging between 30-150 mins at temperatures ranging between $300-500^{\circ} \mathrm{C}$. The system was pressurized to 2 bars by closing the outlet valve while heating the material. Using a specific pyrolysis temperature e.g. $300^{\circ} \mathrm{C}$ and at the end of each residence time, the mass of material remaining unconverted in the reactor was measured and a conversion value evaluated. Also at the end of each residence period the outlet valve was open to allow the flow of condensable vapour through to the condenser where it was condensed to liquid, collected, measured and the yield with respect to the liquid fraction evaluated. The condensates were collected, stored in glass jars and taken to the chemical engineering laboratory at the University of South Africa for chemical analysis using a capillary gas chromatography-mass spectrometer (GCMS-QP2010 SE). A total of 25 samples obtained from the five pyrolysis temperatures and five residence times used, were sent for analysis. Three determinations were made for each sample and an average result reported (Table 1).

Figure 1, is a pictorial view of our batch pyrolysis process, showing the heating and condensation mechanisms. The process is simple and made from materials locally available at the University and in local communities. One of the main objectives behind setting up this pilot unit was to produce samples of the pyrolysis oil in order to be eligible for funding from the government, as this is a pre-requisite.

\subsection{The Attainable Region Approach}

In this article, we applied the Attainable Region (AR) optimization technique to optimize the objective function

TABLE 1: Description of the sample (with respect to the year of the provider change).

\begin{tabular}{l|l}
\hline Parameter & Specification \\
\hline Batch reactor volume (litres) & 100 \\
\hline Batch charge $(\mathrm{g})$ & 1000 \\
\hline Residence times (mins) & $30 ; 60 ; 90 ; 120 ; 150$ \\
\hline Pyrolysis temperatures $\left({ }^{\circ} \mathrm{C}\right)$ & $300 ; 350 ; 400 ; 450 ; 500$ \\
\hline Reactor pressure (bars) & 2 \\
\hline
\end{tabular}

by way of manipulating the input variables in order to give result to maximum process outputs. The objective function was to maximise the conversion as well as the yield of the pyrolysis oil fraction. The AR method is a modern day geometric optimization technique that has been used successfully in the different disciplines of chemical engineering. This approach owes its origins to the field of chemical reaction engineering where Hildebrandt and Glasser (1990) tested it in choosing optimal reactor configurations. Over the years, different researchers (Katubilwa et al. 2011; Danha et al. 2015; Hlabangana et al. 2018) have applied this optimization method on their laboratory scale data with the aim of either minimizing an experimental manipulated variable or maximizing an associated process variable. Since one of the objectives of operating any process is to make profit, the AR technique assists in this regard by way of specifying optimal experimental parameters that will result in either a maximum or minimum condition of the objective function.

The greatest advantage of the AR method is its versatility. The versatility of the approach lies in that it is generic across the field of chemical engineering and a researcher can apply this technique on any process parameter of choice. Smith and Malone (1997) also applied the technique in organic industrial chemistry where they optimized the molecular weights, monomer conversions and residence time in isothermal polymerization systems. In 1998, McGregor et al. used the geometric ideas of the AR method in process synthesis in which they optimized a reactor-separator-recycle system. Godorr et al. (1999) extended the application of the technique in selecting optimal control and operating policies to situations where the rate vector depends on a control parameter. In the year

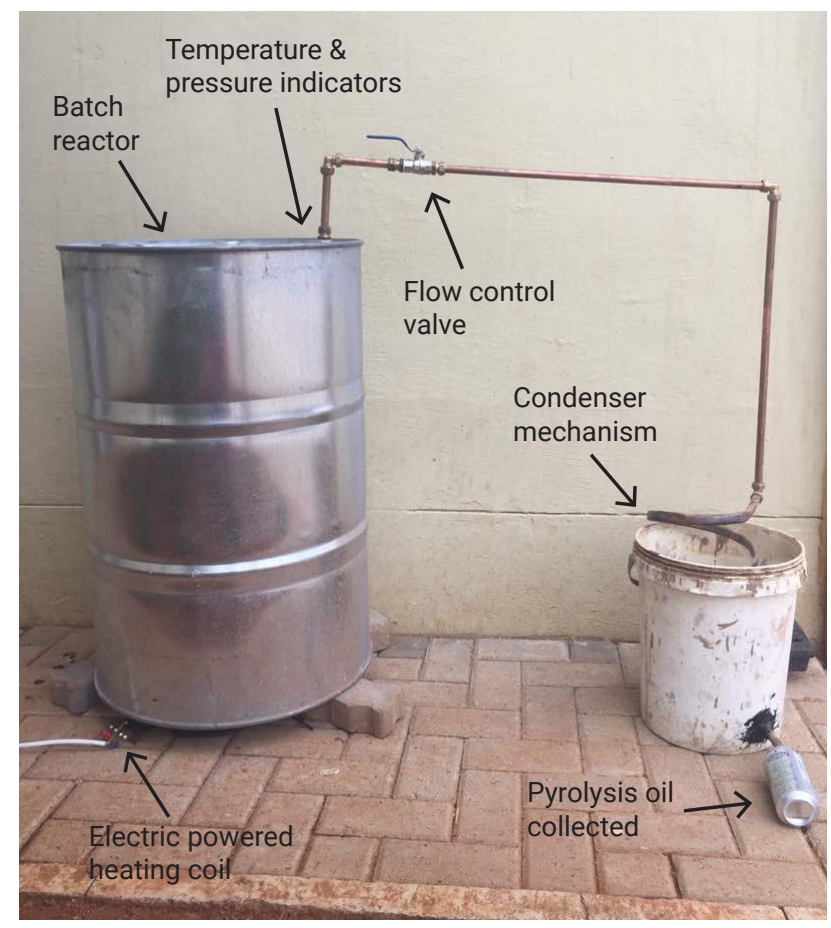

FIGURE 1: Experimental set-up. 
2000, Book and Challagulla used the technique in order to obtain optimal design and operating conditions for the adiabatic oxidation of sulfur dioxide to sulfur trioxide. Nicol et al. (2001) applied the technique in order to find an optimum process design for an exothermic reversible reaction system where provision was made for an external heating and cooling source. Over the years, the technique has been further modified and employed in various fields of process engineering.

\section{RESULTS AND DISCUSSION}

Figure 2 shows a PSD plot of the feed material in the form of a cumulative mass percentage passing versus the sieve size. This plot reveals that the size of the material used as batch feeds were less than $2400 \mu \mathrm{m}$ in size. The size reduction process was performed for a number of reasons namely to: improve handling issues; enable homo- geneous mixing of the feed material; enhance packing of material within the reactor; and increase the surface area for heat to act on the material.

Figure 3 shows an attainable region plot of conversion versus pyrolysis time for different pyrolysis temperatures. The region bounded by the curves and the x-axis is termed the wanted or attainable region and contains combinations of conversion and residence time. The boundary curve offers solutions to the optimisation problem relating to conversion. By applying this technique, Figure 3 reveals that within the conditions of experimental investigation, the optimum conversion attainable is $70 \%$ and this was achieved using a pyrolysis temperature of $450^{\circ} \mathrm{C}$ and a residence time of $2 \mathrm{hrs}$. All the other pyrolysis temperatures gave a maximum value that is less than that recorded for the $450^{\circ} \mathrm{C}$ case. Generally, these experimental results indicate that conversion increased with temperature, and there was an optimum temperature that gave result to maximum

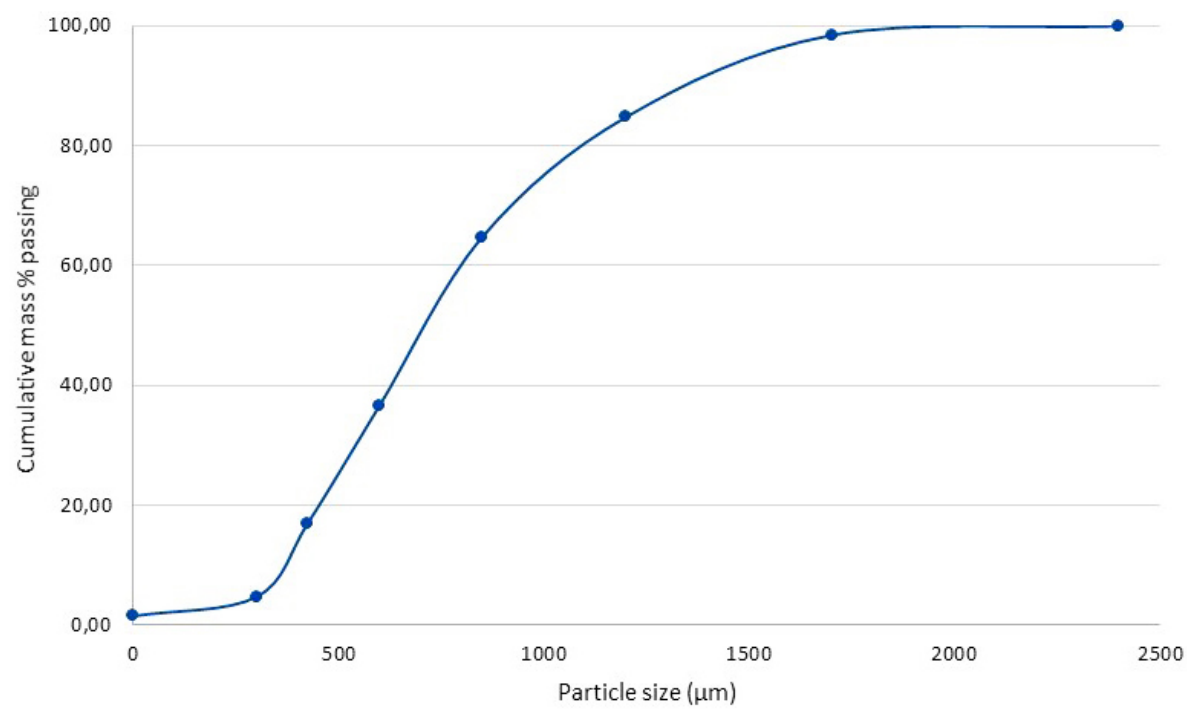

FIGURE 2: Feed particle size distribution.

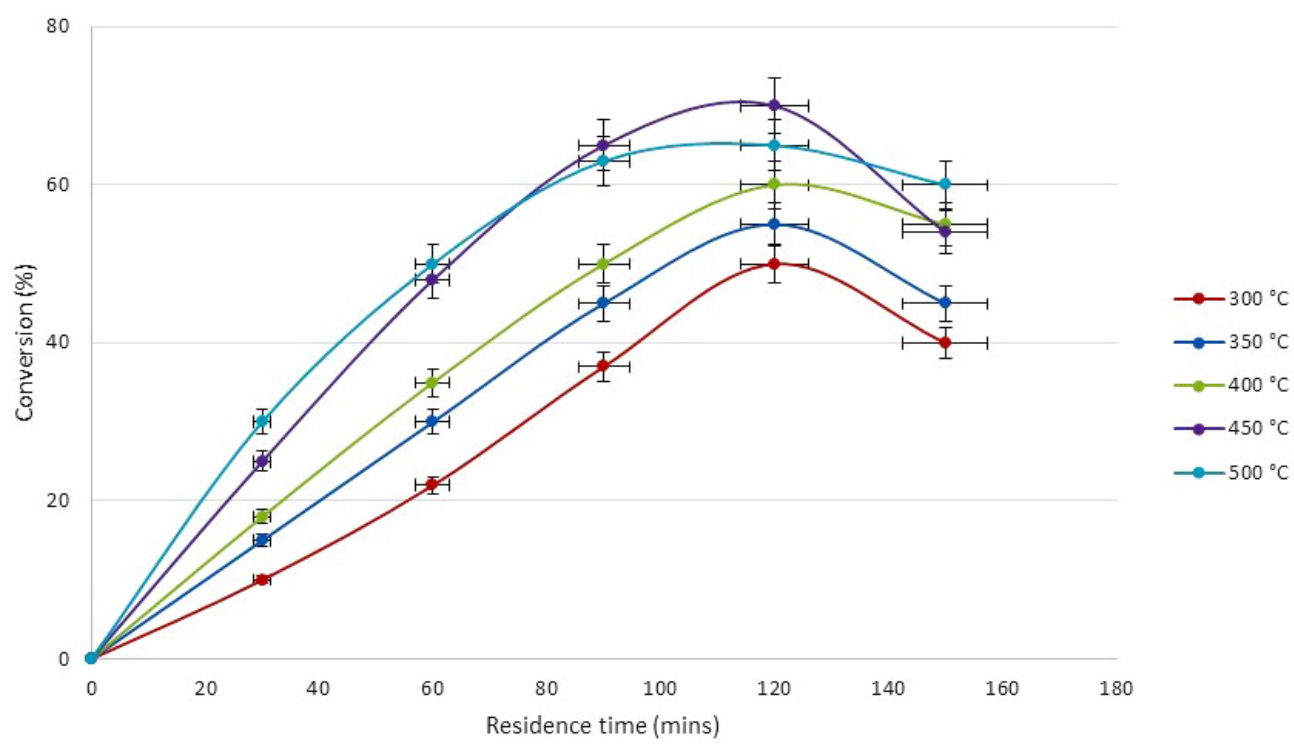

FIGURE 3: Attainable region plot of conversion versus residence time. 
conversion. When temperature was increased beyond this optimum point, there was a decrease in conversion mainly due to a shift in the position of equilibrium towards the reactants.

Figure 4 shows the attainable region plot for yield of the pyrolysis oil fraction versus pyrolysis time for different pyrolysis temperatures. Again, the region bounded by the curves and the $x$-axis denote the wanted or attainable region. Within this space lies different combinations of yield and residence time for the different pyrolysis temperatures. Solution to the yield optimization question lies on the boundary of the curves, specifically at the turning point. Percentage yield of the oil fraction was calculated by taking a molar ratio of the amount of oil produced to the amount of feed material converted multiplied by a unit stoichiometric factor and $100 \%$. Experimental results reveal that the optimum yield of the oil fraction from the A.R plot was found to be $95 \%$, using a pyrolysis temperature of $450^{\circ} \mathrm{C}$ and a residence time of $2 \mathrm{hrs}$. Figure 4 also shows that the molecular vibrations are directly proportional to temperature therefore at higher temperatures the molecular vibrations are increased. The increase in molecular vibrations caused the bonds holding the longer molecules to break into shorter molecular chains (solid to liquid then vapour state). Hence increasing temperature up to $450^{\circ} \mathrm{C}$ increased yield of the oil fraction, but increasing beyond this optimum value resulted in a decrease in the yield of the oil fraction as a result of the increase in the production of the non-condensable gas fraction.

Where truncated sample results are shown in Table 2. Figure 5 and Table 2 show the qualitative and quantitative capillary GC-MS-QP2010 SE analysis results of the pyrolysis oil fraction (density $=0.7 \mathrm{~g} / \mathrm{cm}^{3}$, viscosity $=1.8 \mathrm{~mm}^{2} / \mathrm{s}$ ) obtained at the experimentally determined optimum conditions of pyrolysis time of $2 \mathrm{hrs}$, pyrolysis temperature of $450^{\circ} \mathrm{C}$, and conversion of $70 \%$ resulting in a $95 \%$ yield with respect to the oil fraction.

The capillary GC-MS was an ideal technique to use in determining the volatile and semi-volatile mixture of components that made up the pyrolysis oil. The GC-MS is an instrument that combines two separate techniques namely, the gas chromatography (GC) and the mass spectrometry (MS). The GC part separates the volatiles but can-not always selectively detect them, while the MS part can selectively detect compounds but can-not always separate those (Sneddon et al. 2007).

Figure 5 is a plot of signal intensity, which is the relative abundance of the components versus the molecular weight. Each component in the pyrolysis oil has a unique identification parameter linked to its organic molecular mass. Using a software impeded in the instrument, the peaks from Figure 5 were then matched against a database of spectra for known compounds and each peak was then identified as shown in Table 2.

Figure 5 and Table 2 reveals that there are many different liquid components obtained by the co-pyrolysis of HDPE and LDPE classes of Plastics. This high number of organic components obtained could have resulted from the fact that different pigmented plastics were used as feed material.

A possible way of minimising the number of peaks would have been to pyrolysize either HDPE or LDPE samples separately as well as sorting feed material in terms of colour of their pigments.

\section{CONCLUSIONS AND RECOMMENDATIONS}

From our experimental results it can be concluded that the optimum yield of the oil fraction from the A.R plot was found to be $95 \%$, using a pyrolysis temperature of $450^{\circ} \mathrm{C}$ and after a residence time of $2 \mathrm{hrs}$. Sharuddin et al. (2016) reported similar results in their review article in which they were summarising studies done on plastic pyrolysis. It was also determined that within the conditions of experimental investigation, the optimum conversion attainable is $70 \%$ and this is also achieved using a pyrolysis temperature of $450^{\circ} \mathrm{C}$ and after a residence time of the material in the

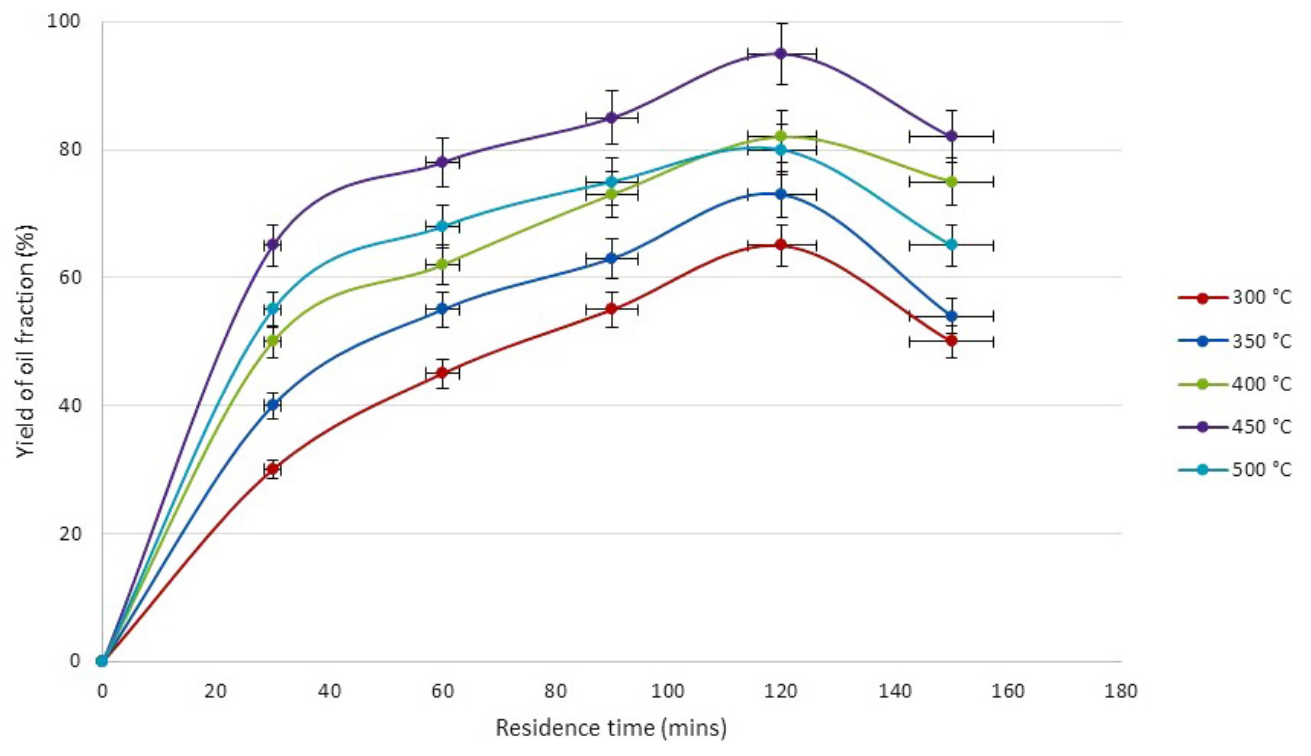

FIGURE 4: Attainable region plot for yield of oil fraction versus residence time. 
TABLE 2: Truncated results of the GC-MS analysis.

\begin{tabular}{|c|c|c|c|c|c|}
\hline Peak \# & Name & R.T. (min:sec) & Weight & Similarity & Unique Mass \\
\hline 169 & 1,2-Di(prop-2-ynyl)cyclohexane & $10: 37.9$ & 160 & 608 & 117 \\
\hline 244 & Cyclopentanecarboxylic acid, 2-amino-, cis- & $19: 42.8$ & 129 & 610 & 56 \\
\hline 76 & Decane, 2,2,3-trimethyl- & 04:01.3 & 184 & 610 & 72 \\
\hline 203 & 2-Octene, 2-methyl-6-methylene- & $13: 31.9$ & 138 & 620 & 109 \\
\hline 274 & Oxalic acid, hexyl octadecyl ester & $26: 25.8$ & 426 & 624 & 153 \\
\hline 32 & Dodecylcyclohexane & $02: 08.9$ & 252 & 625 & 89 \\
\hline 113 & 2-Heptyne-4-one & $06: 44.4$ & 110 & 629 & 68 \\
\hline 27 & 1-Octyn-3-ol, 3-methyl- & $02: 00.9$ & 140 & 634 & 88 \\
\hline 37 & Cyclobutene, 3,3-dimethyl- & $02: 15.9$ & 82 & 635 & 65 \\
\hline 213 & 7-Heptadecyne, 17-chloro- & $14: 54.8$ & 270 & 638 & 117 \\
\hline 38 & Cyanic acid, 2-methylpropyl ester & $02: 17.3$ & 99 & 640 & 60 \\
\hline 171 & Fumaric acid, 3-phenylpropyl tridec-2-yn-1-yl ester & $10: 49.5$ & 412 & 640 & 117 \\
\hline 30 & 4-t-Butylcyclohexylamine & 02:05.6 & 155 & 646 & 105 \\
\hline 153 & 4-Benzoyloxy-1-morpholinocyclohexene & $09: 13.0$ & 287 & 651 & 110 \\
\hline 47 & 2-Butyn-1-ol & $02: 29.8$ & 70 & 652 & 95 \\
\hline 70 & Spiro[2.5]octane & 03:38.8 & 110 & 654 & 110 \\
\hline 114 & 2-Propenoic acid, 2-methyl-, oxiranylmethyl ester & $06: 45.3$ & 142 & 658 & 107 \\
\hline 231 & Cyclohexane, 1-bromo-2-methyl- & $17: 51.9$ & 176 & 659 & 97 \\
\hline 178 & Glycine, furfuryl ester & $11: 24.1$ & 155 & 662 & 97 \\
\hline 5 & 2-Propenoic acid, oxiranylmethyl ester & $01: 31.2$ & 128 & 664 & 45 \\
\hline 191 & 2,7-Octadiene-1,6-diol, 2,6-dimethyl-, (E)- & $12: 31.6$ & 170 & 665 & 71 \\
\hline 192 & 2-Pentene, 4-bromo- & $12: 43.1$ & 148 & 667 & 253 \\
\hline 44 & 2-Butanone, 1-(2-furanyl)-3-methyl- & $02: 24.8$ & 152 & 670 & 86 \\
\hline 50 & $(7 \mathrm{~S}, 8 \mathrm{R})-7-$-Hydroxy-8-amino-trans-anti-trans-tricyclo[7.3.0.0(2,6)] dodecane & $02: 34.0$ & 195 & 672 & 96 \\
\hline
\end{tabular}

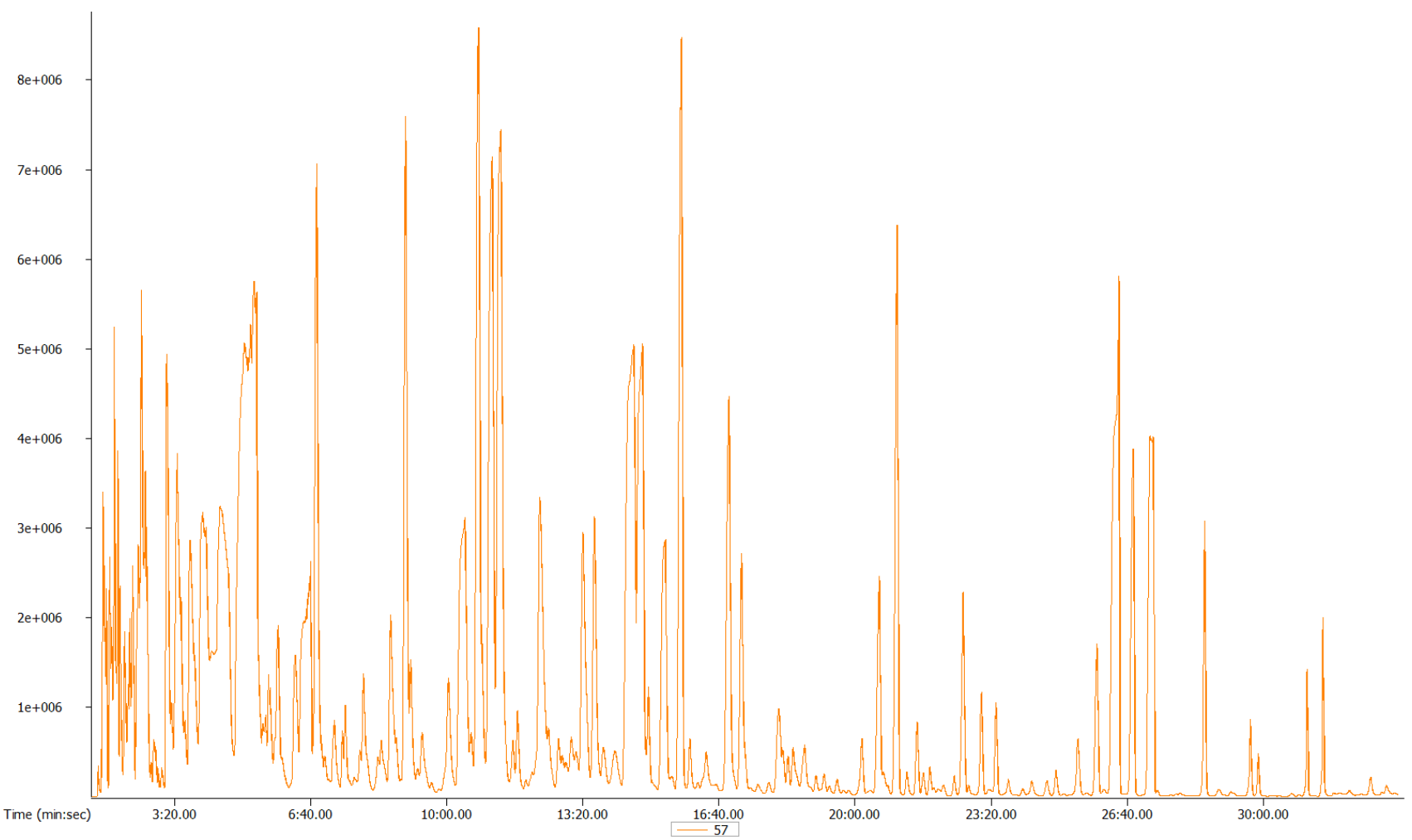

FIGURE 5: GC-MS results of the pyrolysis oil fraction. 
reactor of $2 \mathrm{hrs}$. Hence the objective of optimizing the oil fraction was achieved as we managed to employ the AR technique in specifying the optimal pyrolysis temperature and conversion. Even though the investigation was successful there are possible areas of improvement that we recommend in order to improve the efficiency of the process. A catalyst should be used to improve the degradation process and lower the degradation temperature. As a general rule of thumb in the field of analytical chemistry, no single analytical technique should be used to give comprehensive results in any investigation, we therefore recommend that future studies should include complementary analysis techniques such as the nuclear magnetic resonance spectroscopy (NMR) for completeness.

\section{REFERENCES}

Al-Salem, S.M., Antelava, A., Constantinou, A., Manos, G., Dutta, A., 2017. A review on thermal and catalytic pyrolysis of plastic solid waste (PSW). Journal of Environmental Management 197, 177198.

Al-Salem, S.M., Lettieri, P., Baeyens, J., 2010. The valorization of plastic solid waste (PSW) by primary to quaternary routes: From re-use to energy and chemicals. Progress in Energy and Combustion Science $36,103-129$

Book, N.L., Challagulla, V.U.B., 2000. Inherently safer analysis of the attainable region process for the adiabatic oxidation of sulfur dioxide. Computers and Chemical Engineering 24, 1421-1427.

Chen, D., Yin, L., Wang, H., He, P., 2014. Pyrolysis technologies for municipal solid waste: A review. Waste Management 34, 2466-2486.

Danha, G., Hildebandt, D., Glasser, D., Bhondayi, C., 2015. A laboratory scale application of the attainable region technique on a platinum ore. Powder Technology 274, 14-19.

Das, P., Tiwari, P., 2018. Valorization of packaging plastic waste by slow pyrolysis. Resources, Conservation and Recycling, 128, 69-77.

Das, P., Tiwari, P., 2017. Thermal degradation kinetics of plastics and model selection. Thermochimica Acta, 654, 191-202.

Godorr, S., Hildebrandt, D., Glasser, D., McGregor, C., 1999. Choosing optimal control policies using the attainable region approach. Industrial and Engineering Chemistry Research 38, 639-651.

Guerrero, L.A., Maas, G., Hogland, G., 2013. Solid waste management challenges for cities in developing countries. Waste Management $33,220-232$.
Hahladakis, N.J., Velis, A.C., Weber, R., Lacovidou E., Ournell, P., 2018. An overview of chemical additives present in plastics: and environmentalmpact during their use, disposal and recycling. Journal of Hazardous Materials 344, 179-199.

Hildebrandt, D., Glasser, D., 1990. The attainable region and optimal reactor structures. Chemical Engineering Science 45, 2161-2168.

Hlabangana, N., Danha, G., Mguni, N.G., Madiba, M.S., Bhondayi, C. 2018. Determining an optimal interstitial filling condition: An attainable region approach $327,9-16$.

Katubilwa, F.M., Moys, M.H., Glasser, D., Hildebrandt, D., 2011. An attainable region analysis of the effect of ball size on milling. Powder Technology 210, 36-46

Khaghanikavkani, E., Farid, M.M., 2011. Thermal pyrolysis of polyethylene: Kinetic study. Energy Science and Technology 2, 1-10.

Marshall, R.E., Farahbakhsh, K., 2013. Systems approaches to integrated solid waste management in developing countries. Waste Management 33, 988-1003.

McGregor, C., Hildebrandt, D., Glasser, D., 1998. Process synthesis for a reactor-separator-recycle system using the attainable region approach. Developments in Chemical Engineering and Mineral Processing 6, 21-39.

Nicol, W., Hernier, M., Hildebrant, D., Glasser, D., 2001. The attainable region and process synthesis: Reaction systems with external cooling and heating. The effect of relative cost of reactor volume to heat exchange area on the optimal process layout, Chemical Engineering Science_56, 173-191.

Quek, A., Balasubramanian, R., 2013. Liquefaction of waste tires by pyrolysis for oil and chemicals - a review. J. Anal. Appl. Pyrol. 101, $1-16$.

Sannita, E., Aliakbarian, B., Casazza, A.A., Perego, P., Busca, G., 2012. Medium temperature conversion of biomass and wastes into liquid products, a review. Renewable and Sustainable Energy Review $16,6455-6475$.

Shah, A.A., Hasan, F., Hameed, A., Ahmed, S., 2008. Biological degradation of plastics: A comprehensive review. Biotechnology Advances 26, 246-265.

Sharuddin, S.D.A., Abnisa, F., Daud, W.M.A., Aroua, M.K., 2016. A review on pyrolysis of plastic wastes. Energy conversion and management 115, 308-326.

Singh, N., Hui, D., Singh, R., Ahuja, I.P.S., Feo, L., Fraternali, F., 2017. Recycling of plastic solid waste: A state of art review and future applications. Composites Part B 115, 409-422.

Smith, R.L., Malone, M.F., 1997. Attainable Regions for Polymerization Reaction Systems, Industrial and Engineering Chemistry Research 36 (1997) 1076-1084.

Sneddon, J., Masuram, S., Richert, J.C., 2007. Gas Chromatography-Mass Spectrometry-Basic Principles, Instrumentation and Selected Applications for Detection of Organic Compounds. Analytical letters journal, Taylor \& Francis 40:6 